\title{
Developing Digital Storybook To Improve Children's Language Learning
}

\author{
Hesti Fibriasari ${ }^{1, *}$ Baharuddin ${ }^{2}$ Syamsul Gultom ${ }^{3}$ Syawal Gultom ${ }^{4}$ Martina Restuati $^{5}$ \\ Winsyah Putra Ritonga ${ }^{6}$ Juhriansyah Dalle ${ }^{2}$ Aminuddin Prahatama Putra ${ }^{7}$ Danang \\ Biyatmoko $^{8}$ Ariffin Abdul Mutalib ${ }^{8}$ Cut Nora Azizah ${ }^{9}$ Widya Andayani ${ }^{10}$
}

\author{
${ }^{I}$ Department of French Language Education, Universitas Negeri Medan, North Sumatra, Indonesia \\ ${ }^{2}$ Department of Electrical Engineering, Universitas Negeri Medan, North Sumatra, Indonesia \\ ${ }^{3}$ Faculty of Sport Science, Universitas Negeri Medan, Indonesia \\ ${ }^{4}$ Department of Mathematics, Universitas Negeri Medan, North Sumatra, Indonesia \\ ${ }^{5}$ Department of Biology, Universitas Negeri Medan, North Sumatra, Indonesia \\ ${ }^{6}$ Department of Physics, Universitas Negeri Medan, North Sumatra, Indonesia \\ ${ }^{7}$ Department of Information Technology, Universitas Lambung Mangkurat, South Kalimantan, Indonesia \\ ${ }^{8}$ Department of Biology, Universitas Lambung Mangkurat, South Kalimantan, Indonesia \\ ${ }^{9}$ School of Multimedia Technology and Communication, Universiti Utara Malaysia, 06010 Sintok, Kedah, Malaysia \\ ${ }^{10}$ Department of English Literature, Universitas Negeri Medan, North Sumatra, Indonesia \\ *Corresponding author.Email: hesti@unimed.ac.id
}

\begin{abstract}
Language learning is a crucial element in children's life. As the millennial generation, children nowadays cannot be separated from technology. Therefore, this study was aimed to develop a digital storybook to enhance children's language learning by applying Mayer's principles. This is a collaborative study between researchers from Indonesia and Malaysia. Seventeen children from both countries whose ages ranged from five to seven years old were recruited as the participants. Two experts in children pedagogy were also involved in this study to give feedback from the developed digital storybook. The participants were included in a series of User Experience (UX) Workshops. After the digital storybook has been developed, feedbacks from experts and users were gathered. It was found that this application can improve children language learning. They found new vocabularies and sentences. This digital storybook also introduces them to terms in nature since the stories are about environment. This application can be used by the children but with more interaction with parents and teachers to build more communication.
\end{abstract}

Keywords: Digital storybook, Children's language learning.

\section{INTRODUCTION}

The state of technology has changed. It seeps into the daily lives of people in every town. Especially in the previous decade, the evolution of devices and apps in communication and media [1], as well as the habits associated with them, has been crystal obvious. It alters the manner in which communities carry out their responsibilities. The growth of technology has had an impact on the way people work. While technology is required in everyday chores, it is also vital to develop technologies in such a way that they assist users in their tasks. As a result, numerous design principles have been investigated in order to guide the design process.
Technology also plays a role in the education of youngsters. Nowadays, digital technology is something that most youngsters are exposed to.

In most societies today, digital technology is an integral part of young children's everyday lives [2][3], and UNESCO emphasizes the importance of creativity, curiosity, exploration, sharing, and problem solving when it comes to digital technology [2][4][5]. In Norway, the Framework Plan for Kindergartens emphasizes teachers' pedagogical use of digital technology with children, focusing on digital practices to "encourage the children to play, be creative, and learn" [6], which is in line with the OECD (2017) and UNESCO (2017) 
recommendations [4]. The plan also emphasizes how staff may assist and promote children's development and learning through child-centered playbased pedagogy by drawing on children's interests and experiences; group activities, as well as children's active engagement in society, are highly emphasized in the plan [6]. Therefore, We consider that the process of creating digital stories is a good opportunity for children to experience using digital technology in a collaborative process in which they can express their own meanings and ideas. However, research shows a lack of digital competence among Norwegian kindergarten staff, especially regarding pedagogical use of digital technology. So, this current study focused to develop digital storytelling for children in kindergarten by applying Mayer's Twelve Principles of Multimedia to develop children language learning. This study explained the process and steps how the digital storybook was developed and explored the feedback from the children and experts regarding to the children language learning.

\section{DIGITAL STORYBOOK AND CHILDREN}

Even young children are surrounded by technology; interactions with digital media are becoming an increasingly important aspect of children's everyday lives in classrooms and at home, among other places. Approximately one hour is spent watching television and another hour is spent interacting with other screen media every day for children between the ages of four and six. Many of these goods are promoted as educational (e.g., there are over 65,000 "educational" programs available for the iPad), and the number of technology products marketed to young children and their parents has increased dramatically. Only a few studies have looked at the short- and long-term impacts of technology use on the development of children in their early years. It has been shown that the use of technology by young children is connected with both negative (e.g., obesity; [7]; attention issues; [8]) and favorable outcomes (e.g., academic achievement; [7]). (e.g., math skill development, [9]). To be more specific about language learning, a meta-analysis of 43 research found that technology-enhanced storytelling had a tiny, statistically significant influence on comprehension outcomes but had no effect on measures of vocabulary or engagement [10].

For those interested in the relationship between technology and development, digital storybooks, computer-based adaptations of conventional paper storybooks, are a particularly exciting path to explore. Early literacy skills such as vocabulary, comprehension, and other important early literacy skills are all enhanced when children read traditional storybooks, which has been proven in a large body of research. Traditional storybooks are a well-established context for language learning by young children, and a large body of research reports the positive effects of storybook reading on the development of vocabulary, comprehension, and other important early literacy skills (e.g., [11][12]). Digital storybooks may provide language development benefits that are comparable to, if not superior to, those provided by traditional storybooks. One possible advantage of digital storybooks is that they can include multimedia components (e.g., additional photos, animations, and audio or video clips) as well as interactive features (hot spots) that may aid in the acquisition of a foreign language.

The cognitive theory of multimedia learning proposed by [13] contends that when information is presented in many formats (e.g., words and pictures), greater learning occurs than when the information is presented in a single format (e.g., words alone). The use of multimedia components (such as supplementary photographs, video clips, or animation) in digital storybooks can be used to draw attention to important moments in the story or to convey information about the meaning of a term. When it comes to verb meaning, animation inserted in a digital storybook may be more effective than a static illustration, according to one study. The design of the multimedia message, on the other hand, is quite important. The inclusion of attractive features (for example, decorative pictures) can increase student engagement, yet it may have a negative influence on student learning [14]. [15] describe a coherence effect, which they define as follows: Extraneous information that is included in instruction has a negative impact on student learning. Children may learn less when multimedia components of digital storybooks are included if the multimedia components are unnecessary to the meaning of a word or the plot of the story. Multimedia components, rather than enhancing language acquisition, may detract from or interfere with language learning, according to some researchers. Other scholars have emphasized the significance of relevancy when it comes to multimedia components [16][17][10]. As a result, it appears that certain components of digital storybooks should be evaluated in order to assess their effects on language development.

Digital storybooks, in addition to multimedia components, allow for interactivity. Young children are allowed to choose between interactive forms of digital media, which allow for active participation, and noninteractive forms, which enable just passive participation. In the official position of the National Association for the Education of Young Children, interactive media is never recommended for any of the organization's practice recommendations and may or may not be appropriate for usage with young children. By incorporating interactivity, such multimedia, learners will have an advantage. As tablets like the iPad grow more popular, there are new ways for youngsters to be interactive. Whereas the use of a mouse or keyboard on 
desktop computers is a need, it is unnecessary on tablets for young children to use simple swipes and taps. Interactive components may have the ability to boost interest in storybook content, catch the reader's attention to story elements, give kids an opportunity to contribute to story content, or deliver feedback that depends on their response.

Folkloric in scope, Storytelling is widely popular across the globe. The means of communication is famous. Even adults want to reminisce with their children about their prior lifestyles, how successful they've been, and how they've risen to challenges in their lives. In the meantime, kids are interested in stories because they involve narrative, making use of listening abilities with attention. The passing of a family member is an exceptionally unforgettable event. Stories are more than just an activity: they teach valuable lessons. Young people use the plot to help them face the future. Use the positive aspects of the story to inspire them, and stay away from any problems that their parents might have had to spare themselves. According to [18], a narrative is a reorganized day-to-day experience for which people come to understand the surroundings by using their understanding of stories. Stories are a fundamental tool in the way we conceptualize, analyze, and evaluate circumstances, experiences, and ideologies, all of which leads to the generation of new ideas and knowledge.

Stories are a vital component of our communications because they communicate messages, but also because they help us to clarify those meanings [19]. Storytelling itself establishes and establishes ties between the audience and the narrator. The family in the preceding passage has intimate, loving, appreciative, and helpful relationships, which comprise elements of kindness, consideration, responsibility, and confidence.

\section{CONCEPT OF DIGITAL STORYTELLING IN LEARNING BY DOING}

It was very interesting to listen to storytelling. But it is more interesting to have the storytelling supported with pictures. A story is much easier to get into correct representation with helps of pictures. In the past, people utilized printed pictures, kept in photo albums to represent the related pictures. Later, the pictures were made available in digital form. With the pictures, a narrator (for a storytelling) can reduce the amount of words to express [20]. The benefits of pictures are wealth.

Then, not only the pictures digitalized, but also the narrations [21]. The narrators record their voice, and distribute the records to the listeners to play during free time or when necessary. Gradually, the storytelling becomes more sophisticated, growing together with the past formats in analogue face-to-face environment. Currently, the storytelling can be found in fully digital, which not only applies audio and pictures, but also more precisely they are equipped with navigation abilities [22]. Users can interact with them, which are developed with special behaviors, feeding back to user responses [23].

Digital storytelling is "...the modern expression of the arts of storytelling...digital stories derive their power through weaving images, music, narrative and voice together, thereby giving deep dimension and vivid color to characters, situations, and insights...”. [24]

Based on the above discussions, digital storytelling can be understood as a type of material that incorporates audio and visual elements, with textual strength into an aesthetic presentation. It is like movies, but in the form of interactive application. As opposed to the conventional storytelling, it is composed of still and moving images, text, sounds, music, and voice narration to depict an important event, person, position, or condition. As a revolution [25], digital storytelling integrates all elements properly so that it conveys contents from the heart [25].

Electronic learning is expanding, and taking place in most educational premises from schools to HLI and training centers. Learning Objects (LO) are available in many formats such as text-only, audio-only, courseware, video, animation, virtual reality, and reality learning media [26]. Digital storytelling can be another famous format of LO in near future. Many authors have proposed digital storytelling in education, such as can be seen in works by [27][28][22]. In fact, the digital storytelling has gone on mobile platforms a decade ago (Frohlich et al., 2009).

On the other hand, Johnson (2009) found that involving children in making digital storytelling for use in school is very promising. It is very user-centered, and in addition it reduces cost, and can be utilized not only by sophisticated schools but also schools with limited technological setting, budget, and competence. This argument supports the project carried out by [28].

The digital storytelling can also be utilized in educating slow learners. The slow learners are a group of people with special problem. They should be treated specially. This is in line with one of virtues of digital media that "such individuals should be regarded as unique set of problems (and strengths) and as such no one education model or indeed one set of materials can cover all". Based on the above argument, [29] carried out a study to find online territories for the slow learner. She concluded that elements in digital storytelling can be utilized to win the slow learners situation.

On the other hand, [30] developed digital storytelling as a classroom strategy for digital literacy learning. They deploy the digital storytelling in natural setting to enhance students' ability to absorb contents in documents on screen. Their arguments are in line with works by [31] at International Children's Digital Library. It was found 
that the digital storytelling can help in absorbing the content and fosters social relationships with helps of various media elements. Moreover, the storyline creates relationships between the contents and the readers.

With references to the discussions in the previous paragraphs, this study designs and develops a digital storybook that educates children about morale in life. To ensure users experience while interacting with the digital storybook is well-supported, this study applies the principles of multimedia by Mayer. The challenge is how to ensure the principles are appropriately applied in the digital storybook. To address that, this study carries out all tasks through a series of User Experience (UX) Workshops.

\section{LANGUAGE LEARNING FROM DIGITAL STORYBOOKS}

New study findings show that digital storybooks can be useful in language acquisition. In a research synthesis of 27 studies, [32] found that students who used electronic books as opposed to paper books had a smallmoderate impact on comprehension outcomes. In an effort to get to the bottom of this, researchers began to evaluate specific studies that look at language learning from digital storybooks. The results, however, indicated mixed results. Other researches have revealed no differences in vocabulary learning [33][34][35]. With regard to the outcome of story comprehension, children have demonstrated similar story comprehension with the two different delivery formats (e.g., print vs. digital) [36]. Some children, however, demonstrated worse story comprehension after experiencing digital storybooks than with traditional storybooks [37][38]. When it comes to digital storybooks, those that include video components or dictionary functions have provided the most assistance to young learners in the area of vocabulary growth [39][40][41]. Children with language disability learnt more vocabulary from static digital storybooks than from video ones. When Smeets et al. repeated the experiment, they found that background music and sound effects interfered with the acquisition of words, suggesting that certain digital storybook aspects could hinder learning. The results are in agreement with the Mayer and Moreno effect, outlined before [15]. Learning benefits when multimedia components follow the instructional objective (for example, when dictionary elements assist with word learning). To the contrary, irrelevant multimedia components (e.g., background music) might negatively impact learning.

While few research have directly explored the importance of interaction in language learning from digital storybooks, we can nevertheless make educated guesses based on previous studies. Preschoolers in interactive and noninteractive digital storybooks learned words and comprehended stories equally. An interactive version of the glossary includes hot spots in which definitions are supplied for the language that users are examining. After experiencing interactive digital storybooks, children learnt more vocabulary than with animated or static storybooks. On measures of story comprehension, no significant differences were seen across groups. With interactive e-books with multiple choice questions on target vocabulary, children learnt more vocabulary terms than when e-books did not include questions. It's worth pointing out that these digital storybooks [42][43] include interactive components meant to aid vocabulary learning. These studies instead give evidence that stories interwoven with interactive elements in digital books can aid in language acquisition.

One of the few examples of an investigation of interactive and non-interactive digital storybooks was given by [45]. Since digital storybooks incorporated interactive components that were designed to be entertaining rather than instructional, they were described as digital storybooks with amusing interactive features. Incorporating unconnected animations and soundtracks into the main narrative would make the stories much more entertaining for kids. This study found that kids who were exposed to interactive digital storybooks were no better at comprehending stories than children who were not exposed to interactive digital storybooks. However, as predicted by the coherence effect, interactives did not help tale comprehension.

To do exploratory research into the impacts of interactive and non-interactive digital storybooks on word learning and story comprehension, the present study was designed as a study investigating interactive and non-interactive versions of digital storybooks. These findings contradict those of the [42][43] studies, which analyzed interactive training and found that it benefited language learning. Because the two experimental settings differed solely in the inclusion of interactive features, it was possible to isolate the influence of interactivity. Apart from that, the digital tale's presentation included the use of images, animations, and exposure to story text. An understanding of the role of interactivity itself, and not just interaction as a component of education, can be further advanced by focusing on the interactive features used in the current study. Interaction rather than instruction is what is likely to be responsible for the observed disparities in word learning and tale comprehension.

This study, unlike the prior studies, which used researcher-created media (such as [34][42][43]), utilized commercially available digital storybooks for both intervention and assessment. Instead than investigating the way language learning is affected by digital storybooks specifically created for instructional purposes, the current study focuses on language learning that can occur as a result of using common digital storybooks. 


\section{METHOD}

\subsection{Participants}

Participants from this study were a group of 17 children between five to seven years old. They were recruited from a public kindergarten in Malaysia and Indonesia. Families of children in kindergarten classrooms at both countries were invited to give permission for their children to participate in the study. The children then were involved in some series of User Experience Workshop to develop the digital storybook. In the workshop, their tasks were centralized on feeding back to tasks they were asked to do. During the workshop, their reactions and feedback were recorded as input for the betterment of design artefacts and hence actualizing the digital storybook. Besides the children as the participants, this study also recruited 2 experts in children pedagogy. These experts gave their arguments and suggestion for the developed digital storybook. large amounts of white space within the graphic;

\subsection{Research Procedures}

Wherever possible try to ensure that the size of the text in your figures (apart from superscripts/subscripts) is approximately the same size as the main text (11 points).

\subsection{Workshop 1 - gathering features}

Workshop 1 was organized with the goal to gather features for the digital storybook. The participants were shared with five digital storybooks (Figure 1). They were tasked to find some information in the digital storybooks. For that purpose, they discussed together. The session was so lively. It was video-recorded, for archive. Notes were taken, especially the way they interact with the digital storybook. This study focused on features related to principles of multimedia by Mayer. At the end of the workshop, the gathered features were discussed with the experts to gather their feedback.

The five digital storybook in Figure are designed with varying interaction design styles. They are used in the UX workshops to enable the workshop participants experience different elements and features so that this study could gather comprehensive details in the workshops.

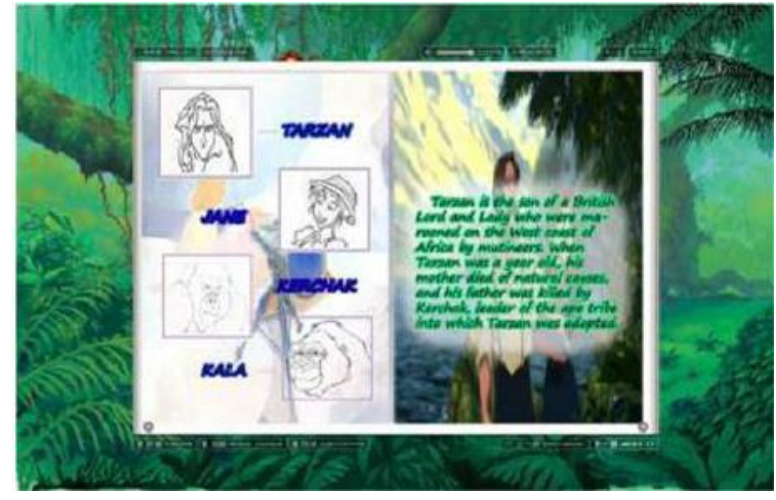

Figure 1 Digital storybooks distributed in the UX workshops.

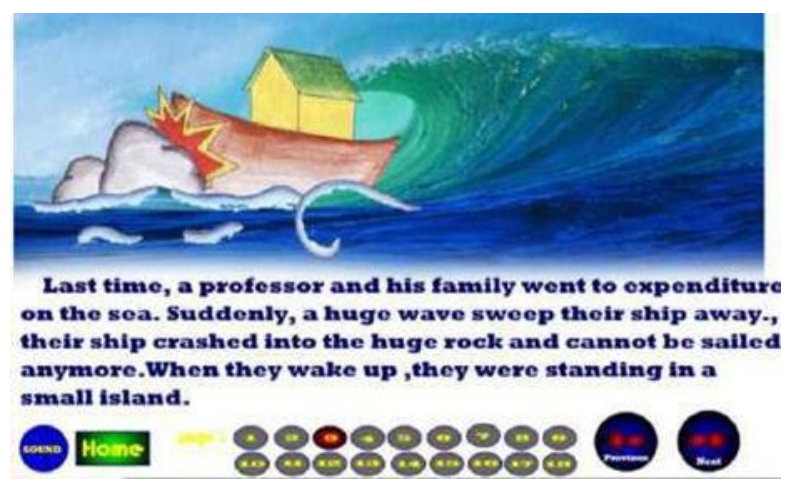

Figure 2 Digital storybooks distributed in the UX workshops.

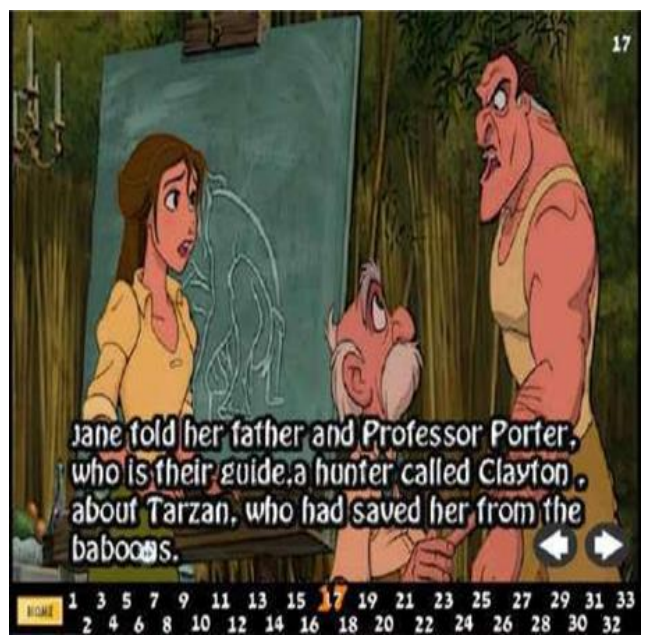

Figure 3 Digital storybooks distributed in the UX workshops. 


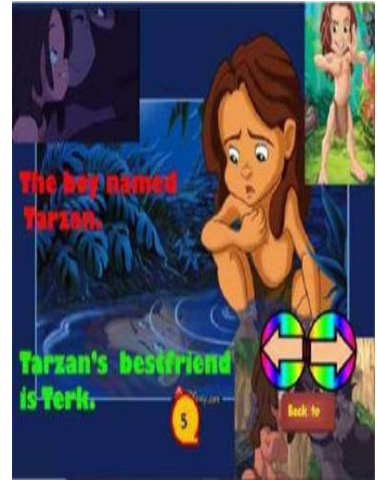

Figure 4 Digital storybooks distributed in the UX workshops.

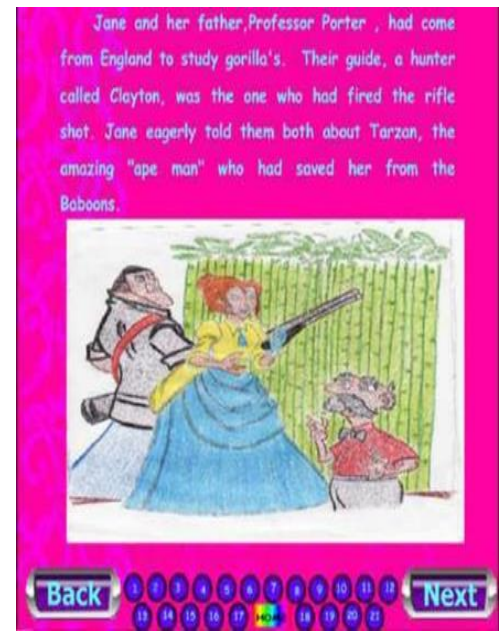

Figure 5 Digital storybooks distributed in the UX workshops.

\subsection{Workshop 2 - graphic}

A week later, the participants gathered again, in Workshop 2, with the goal for this study to design the graphics required in the digital storybook. The similar digital storybooks (in Figure 1) were utilized for understanding the needs for graphics. In the beginning, the workshop kicked-off with pre-determined ideas on the concept of the desired digital storybook. Consequently, the ideas were brainstormed, and led to an agreed decision. Having agreed on the decision, this study worked on the designing work. At the end of the workshop, the materials were presented to the experts, to gather their feedbacks.

\subsection{Workshop 3 -audio}

Then a week later, Workshop 3 was organized. In this workshop, the goal was to make audio for the digital storybook. In this workshop, similarly the digital storybooks in Figure 1 were distributed to the participants. Based on those digital storybooks, the needs for the narration were gathered. Eventually, the narration for the on-screen text were recorded. Besides, this study also made appropriate sound effects.

\subsection{Workshop 4-composition}

Having gathered the graphics and audio for the digital storybook, they were composed in Workshop 4. The composition task was based on reactions of the participants over the similar digital storybooks. Among the aspects classified in composition are structure and layout.

\subsection{Workshop 5 - navigation}

In the following week, Workshop 5 was conducted, aiming at realizing the navigation element in the digital storybook. It ended in just half-a-day.

\subsection{Workshop 5 -presentation}

On the same day with the Workshop 5, Workshop 6 was conducted in the afternoon. In the workshop, the designed and developed digital storybook was presented. Feedback by the experts were gathered for improvement. The experts were academia who have been researching and teaching human-computer Interaction for at least five years.

\section{RESULT AND DISCUSSION}

After the all processes and procedures were completed, a digital storybook; with improved-design based on response by children and experts in the UX Workshops; has been outcome. It is designed for children between five and seven years old. The content was adapted from an old folks' story. Samples of the books are visualized in Figures 2 through 5. Generally, it is seen in the figures that the developed digital storybook applies consistent structure and layout; navigation at the top, while the content is at the centre of the screen. The page number is stated at the same place, similarly on all pages.
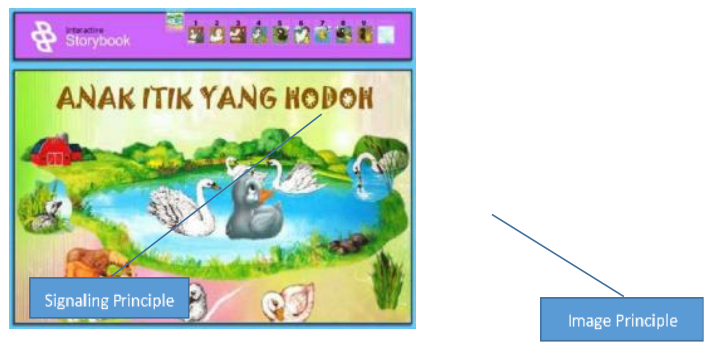

Figure 6 Image Principle and Signalling Principle.

Figure 6 shows the front page, the page users view when they open the digital storybook. The title is "Anak Itik Yang Hodoh". The front page is quite illustrative, with coherence between the title and the graphical metaphor. We could put a talking head to deliver the story, but it is better to use graphical representatives, to better engage the users (children). At the top, the 
navigation button is made always available. The navigation is designed in the form of miniature page (forming the buttons). As to signal the function, the buttons react to mouse-over (like the left-most uplifts itself). This page demonstrates the application of image principle and signalling principle. They are applied throughout the entire digital storybook.

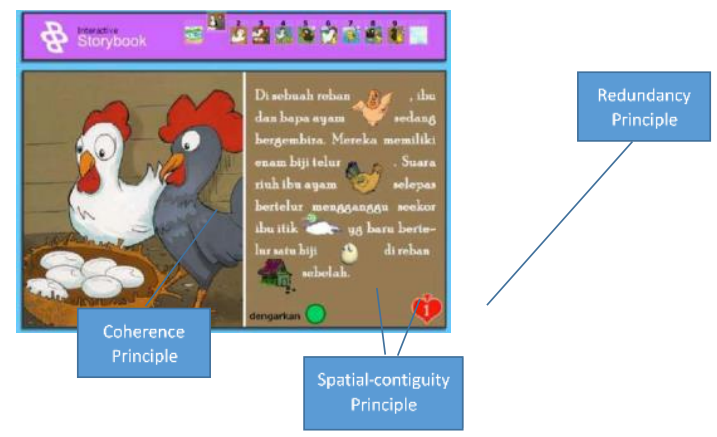

Figure 7 Coherence Principle, Spatial-contiguity Principle, and Redundancy Principle.

In Figure 7, the Coherence Principle, Redundancy Principle, and Spatial-contiguity Principle are applied. They are applied in the use of graphic, text, and audio elements. The graphic is ensured clear, no clutter, just adequate to visualize the gist of the meaning. The Coherence Principle states that extraneous and distracting elements are taxing, especially for this book because the users are five to seven years old children, who are still developing their reading skill. Therefore, all graphics in the entire digital storybook are designed without too much unnecessary decoration.

For the purpose of supporting user experience, the Redundancy Principle is also applied. It states that users will perform better if graphics are coupled with narration rather than graphics with narration and text. As a consequence, for this digital storybook two elements are provided by default, and the third is provided as an option. As children are still developing their reading skills, hence graphic and text are provided by default, while narration is an option to enhance their experience.

In the entire digital storybook, the text element is put physically closed with the respective graphic, side-byside, not in different pages. According to Spatialcontiguity Principle, it is effective in minimizing users (children five to seven years old) cognitive load.

Those three principles are applied throughout the entire digital storybook.
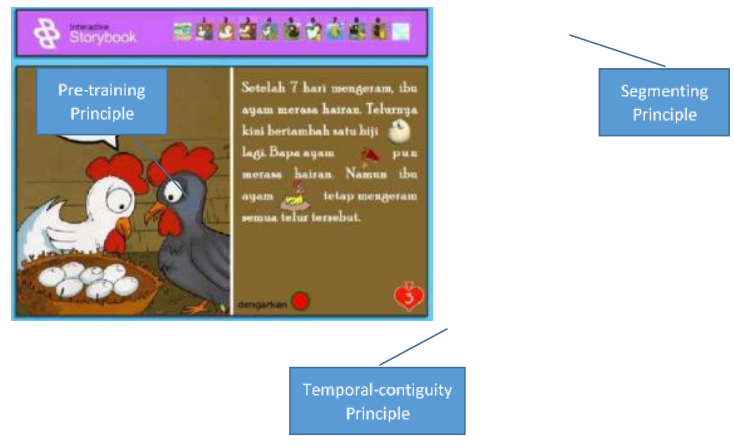

Figure 8 Pre-training Principle, Segmenting Principle, and Temporal-contiguity Principle.

According to Pre-training Principle, users perform better when they know some elements in the digital storybook. Thus, the common characters, i.e. chicken and duck, are used in the digital storybook. The story is also made closed to users' environment, and are chunked into small parts. This ensures users cognitive is not overwhelmed. It fits with the Segmenting Principle. The narration is provided as an option, to allow users listen to it together with reading the text (recommended by Temporal-contiguity Principle). It benefits in twofold: one, users can choose either to listen or read, and second, users can check their reading through the narration. This three principles are applied (as seen in Figure 4) in all pages in the digital storybook. The narration button changes its color when clicked, which signals or gives cue to the user (appropriate with Signalling Principle).

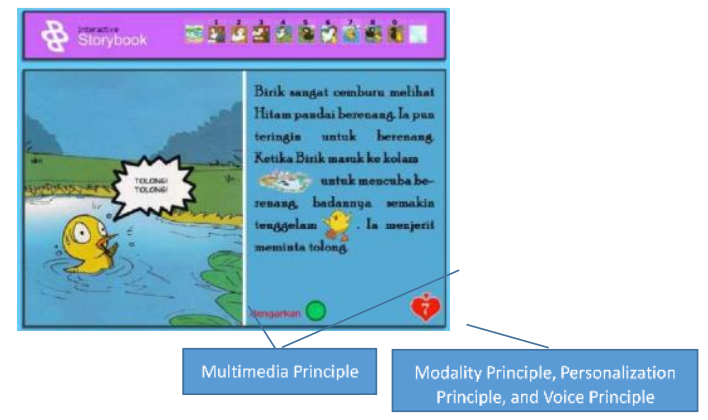

Figure 9 Multimedia Principle, Modality Principle, Personalization Principle, and Voice Principle.

Regarding the narration, the digital storybook applies Modality Principle, Personalization Principle, and Voice Principle (Figure 5). According to Modality Principle, users perform better with visual and narration over visual and text. Therefore, the narration is provided as an option. As to enhance that, the narration is made using human voice, not robot. It is recommended in Voice Principle. Beyond that, the narration is expressed in a conversational voice, not too formal, which fits the Personalization Principle. These are applied throughout the entire digital storybook. 


\subsection{Collective Feedback from Experts}

The digital storybook was presented in Workshop 6, for viewing by experts. Based on their expertise, they are happy with the developed storybook. In detail, their comments are classified into themes, as listed in Table 1.

Table 1 Experts' feedbacks.

\begin{tabular}{|l|l|}
\hline Content & $\begin{array}{l}\text { Both experts expressed that the } \\
\text { contents, chunked into small parts, are } \\
\text { appropriate for the children. On every } \\
\text { page, there is no use of scroll bar, good } \\
\text { in supporting children's tasks. }\end{array}$ \\
\hline $\begin{array}{l}\text { Multimedia } \\
\text { elements }\end{array}$ & $\begin{array}{l}\text { This digital storybook does not contain } \\
\text { much animation. It is a good choice. } \\
\text { The animated gif in the text is enough } \\
\text { to engage the children's cognitive. }\end{array}$ \\
\hline Navigation & $\begin{array}{l}\text { In the entire book, there is only one } \\
\text { place for navigation, for moving pages. } \\
\text { This is excellent. Users do not have to } \\
\text { filter for which one to attend to, } \\
\text { unnecessarily. On top of that, some } \\
\text { signalling on the navigation button } \\
\text { enhances user experience, and is quite } \\
\text { aesthetic. }\end{array}$ \\
\hline Interaction & $\begin{array}{l}\text { The simple graphics, human-voice } \\
\text { informal narration, and some visual } \\
\text { cues are excellent. Children, who are } \\
\text { still developing their reading skills need } \\
\text { assistance in various ways, and these } \\
\text { are among the assistance that are } \\
\text { potentially develop their learning skills } \\
\text { and cognition. }\end{array}$ \\
\hline $\begin{array}{l}\text { In the entire book, there is only one } \\
\text { place for navigation, for moving pages. } \\
\text { This is excellent. Users do not have to } \\
\text { filter for which one to attend to, } \\
\text { unnecessarily. On top of that, some } \\
\text { signalling on the navigation button } \\
\text { enhances user experience, and is quite } \\
\text { aesthetic. }\end{array}$ \\
\hline
\end{tabular}

\subsection{Collective Feedbacks from Users}

For the purpose of gathering feedback on the designed and developed digital storybook, a different group of children between five and seven years old was gathered. It was decided not to involve the group that involved in the designing and developing process to ensure the gathered feedback was not affected by the experience in the designing process. Therefore, the feedbacks in Table 2 were expressed by the children who first time dealt with the designed and developed digital storybook.
Table 2 Experts' feedbacks.

\begin{tabular}{|c|c|}
\hline Content & $\begin{array}{l}\text { We like this story, it is easy to follow. } \\
\text { The animated picture in the text is } \\
\text { interesting... I like it... I can } \\
\text { understand the story well, because they } \\
\text { are short, and the language is easy for } \\
\text { me to understand. } \\
\text { If I want to check my reading, I can } \\
\text { listed to narration, just by clicking the } \\
\text { button. It is so easy, and interesting. } \\
\text { The pictures in all pages are so nice. } \\
\text { The text and pictures are always } \\
\text { supporting each other, very interesting. }\end{array}$ \\
\hline $\begin{array}{l}\text { Multimedia } \\
\text { elements }\end{array}$ & $\begin{array}{l}\text { I like the characters, I know they are } \\
\text { chickens. There is also a duck. They } \\
\text { swim and play in a garden. } \\
\text { I like this digital storybook. My friend } \\
\text { can choose to listen to the narration. } \\
\text { The narration is nice because it speaks } \\
\text { like my teacher. I like the pictures } \\
\text { because they are clean. The text are also } \\
\text { short, straight to the point. }\end{array}$ \\
\hline Navigation & $\begin{array}{l}\text { If I want to move to another page, I just } \\
\text { need to click the desired button. Just a } \\
\text { single-click. Interesting, because I do } \\
\text { not have to click buttons unnecessarily. } \\
\text { It helps me to move pages. It also stays } \\
\text { at one place, hence I can attend to them } \\
\text { confidently. }\end{array}$ \\
\hline $\begin{array}{l}\text { Interaction } \\
\text { Style }\end{array}$ & $\begin{array}{l}\text { I always like to listen to narration, to } \\
\text { check my reading skills. I read first, } \\
\text { after that, I click the button so that the } \\
\text { book reads for me. This is interesting. } \\
\text { I am happy interacting with the book. } \\
\text { I feel relax reading the book. }\end{array}$ \\
\hline Overall & $\begin{array}{l}\text { The digital storybook is awesome. I like } \\
\text { the pictures, the story, and the buttons } \\
\text { because they entertain me. I also like } \\
\text { the narration because I can opt, whether } \\
\text { to listen or not. The storybook also } \\
\text { responds to me swiftly, like when I } \\
\text { click the page buttons or to listen to } \\
\text { narration. }\end{array}$ \\
\hline
\end{tabular}

The participants are currently investigating the four things that the digital tale book can help them with when it has been implemented. The professionals believe that the use of the device is straightforward, which makes it easier for the children to use it. The children expressed their approval of the digital storybook's stories. As well as being easy for them to grasp, the language is also similar to what they know and the most crucial aspect is that they like the images. According to the experts, this 
digital storybook is perfect for children who have difficulties with reading. While discussing their opinions on characters and stories, the children noted that they like the figures and characters in the stories. It makes sense because their teacher does, in fact, talk like that. The results of studies investigating the efficacy of interactive storybooks for language learning in classrooms demonstrate their usefulness in that respect [42]. While it is imperative to analyze the specific qualities of these digital storybooks, it is critical to remain skeptical when evaluating these storybooks' capabilities. Features that encourage language acquisition should be developed using sound evidence and build on a similar foundation of research for multimedia training. Similar to Mayer's theory of multimedia learning (as presented in 2005), a multimedia message needs to be designed properly. The study by [42] found that children acquired more words when they were presented with multiple choice questions, as opposed to questions that offered definitions, referred to as "hotspots." A recent study [44] found that digital storybooks help children with language impairment and children from low-income families improve their language skills.

A child's growing use of digital media necessitates an investigation into how language acquisition might be promoted through this media. In the current study, preschool children gained knowledge of two words after playing with a commercially available digital storybook. Several research studies have examined interactions between adults and children when reading a storybook. For example, researchers have discovered dialogic reading tactics, such as questioning and prompting, which may promote language learning. Though children are often more likely to employ these facilitative behaviors when they are using digital storybooks, adults may be less likely to utilize these behaviors during their experience with digital storybooks [38]. The use of digital storybooks as a supplement to, rather than a replacement for, high-quality adult-child interactions around storybooks may be beneficial. To help gather information, we read through several commercially accessible digital storybooks. When comparing the many digital storybooks, it was discovered that the qualities of each book might change greatly depending on whether they are intended for language acquisition. For digital storybooks, frequently games and activities unrelated to the narrative were found, or sometimes impeded the storyline. Regardless of their marketing claims, the majority of those educational programs failed to follow the evidence-based principles of learning. It is obvious that the creators and distributors of digital storybooks for youngsters have an extremely difficult task ahead of them.

\section{CONCLUSION}

Use of the twelve principles of multimedia is especially impressive in the digital storybook. While the UX workshops were stressful, especially when dealing with the young children, the design process was difficult, especially since there were a large number of inexperienced participants. It was difficult for the participants to handle their work efficiently in the workshops. Despite this, the end result succeeds admirably in meeting the user's requirements. A key to the workshop's success is the holistic engagement that it encourages. Participation was widespread across all participants in the whole UX Workshops study. The capability this system provides allows this study to be certain about the data that they need in order to achieve the aims of the UX Workshops.

It may be concluded from this study that a product process should include attention to enjoyment, efficiency, and fun. Sustainable products must not only function but also give a positive user experience. People should be included in the process of designing customer experiences, therefore having to deal with user experience is unavoidable. Users are responsible for setting requirements. It is possible to be sure that the gathered need is correct due to the presence of real users in the workshops (design sprint cycles).

Inference may be drawn from the study, which claims that interactivity must be created specifically with an instructional goal in mind in order to facilitate meaningful language learning. Future research may investigate the different characteristics that enhance the successful implementation of interactive storytelling digital storybooks. The increases found in the earlier research of incidental word learning from conventional storybooks held true for both groups of children. These modest improvements lead us to believe that digital storybooks could possibly serve as an alternative to, rather than a supplement to, quality adult-child interactions around storybooks. B1, etc.

\section{REFERENCES}

[1] A.F. Rosmani, A.A. Mutalib, S.M. Sarif, The Evolution of Information Dissemination, Communication Media, and Technology in Malaysia, Journal of Physics: Conference Series, vol. 1529, IOP Publishing, Bristol, UK, 2020, pp. 110. DOI: http://doi.org/10.1088/1742$\underline{6596 / 1529 / 2 / 022044}$

[2] S. Chaudron, D.G. Rosanna, G. Monica, Young Children (0-8) and Digital Technology: A Qualitative Study across Europe, European Union, Luxembourg, Europe, 2018.

[3] Medietilsynet, Foreldre og medierunders $\varnothing$ kelsen 2018: foreldre til 1-18-åringer om medievaner og 
bruk [Parents and the Media Survey 2018: Parents of 1-18-Year Olds About Media Habits and Usage], The Norwegian Media Authority, 2018.

[4] I. Kalas, Recognizing the Potential of ICT in Early Childhood Education: Analytical Survey, UNESCO Institute for Information Technologies in Education, Moscow, 2010.

[5] OECD, Starting Strong V: Transitions from Early Childhood Education and Care to Primary Education, OECD Publishing, Paris, 2017. doi:10.1787/9789264276253-en

[6] Udir, Framework Plan for Kindergartens, The Norwegian Directorate for Education and Training, 2017.

[7] S.E. Anderson, R.C. Whitaker, Household Routines and Obesity in US Preschool-Aged Children, PEDIATRICS, vol. 125, 2010, pp. 420-428. DOI: https://doi.org/10.1542/peds.2009-0417

[8] D.A. Christakis, F.J. Zimmerman, D.L. DiGiuseppe, C.A. McCarty, Early television exposure and subsequent attention problems in children, PEDIATRICS, vol. 113, 2004, pp. 708-713. DOI: http://dx.doi.org/10.1111/j.1365-

2214.2004.00456_4.x

[9] S. Pasnik, C. Llorente, Preschool Teachers Can Use a PBS KIDS Transmedia Curriculum Supplement to Support Young Children's Mathematics Learning: Results of a Randomized Controlled Trial. Summative Evaluation of the CPB-PBS "Ready To Learn Initiative", Education Development Center and SRI International, 2013.

[10] Z.K. Takacs, E.K. Swart, A.G. Bus, Benefits and pitfalls of multimedia and interactive features in technology-enhanced storybooks: A meta-analysis, Review of Educational Research, vol. 85, 2015, pp. $1-42$. DOI: https://doi.org/10.3102\%2F0034654314566989

[11] S.E. Mol, A.G. Bus, M.T. de Jong, Interactive book reading in early education: A tool to stimulate print knowledge as well as oral language, Review of Educational Research, vol. 79, 2009, pp. 979-1007. DOI:

https://doi.org/10.3102\%2F0034654309332561

[12] National Early Literacy Panel, Developing early literacy: Report of the national early literacy panel, National Institute for Literacy, Washington DC, 2008.

[13] R.E. Mayer, Cognitive theory of multimedia learning, in: R.E. Mayer (Ed.), The Cambridge handbook of multimedia learning, Cambridge University Press, New York, 2005, pp. 31-48.
[14] R.E. Mayer, Incorporating motivation into multimedia learning, Learning and Instruction, vol. 29, 2014, pp. 171-173. DOI: https://doi.org/10.1016/j.learninstruc.2013.04.003

[15] R.E. Mayer, R. Moreno, Nine ways to reduce cognitive load in multimedia learning, Educational Psychologist, vol. 38, 2003, pp. 43-52. DOI: http://dx.doi.org/10.1207/S15326985EP3801_6

[16] M.T. de Jong, A.G. Bus, How well suited are electronic books to supporting literacy? Journal of Early Childhood Literacy, vol. 3, 2003, pp. 147164.

DOI: https://doi.org/10.1177\%2F14687984030032002

[17] K. Roskos, J. Brueck, S. Widman, Investigating analytic tools for e-book design in early literacy learning, Journal of Interactive Online Learning, vol. 8, 2009, pp. 218-240.

[18] M. Keaveney, N. Livo, S. Rietz, Storytelling/Process and Practice, Western Folklore, vol. 46, 1987, p. 134. DOI: https://doi.org/10.2307/1499935

[19] L. Schäfer, Investigations on digital storytelling, Verlag Dr. Müller, Saarbrücken, Germany, 2008.

[20] J. Lambert, Digital storytelling: Capturing lives, creating community, Center for Digital Storytelling, Berkeley, 2002.

[21] D. Churchill, Digital storytelling, Retrieved September 12, 2007, from http://www.learnactivity.com/ds/

[22] W.A. Widjajanto, M. Lund, H. Schelhowe, "Wayang authoring": A web-based authoring tool for visual storytelling for children, in: Proceedings of The 6th International Conference on Advances in Mobile Computing \& Multimedia (MoMM2008), Austria, 2008, pp. 464-467.

[23] A. Cooper, R. Reinmann, D. Cronin, About Face 3: The essentials of interaction design, Wiley Publishing Inc, USA, 2007.

[24] Digital Storytelling Association, Digital Storytelling, 2002, retrieved on 6 March 2010 from http://www.dsaweb.org/

[25] D. Meadows, Digital Storytelling: Research-based practice in new media, Visual Communication, vol. 2, 2003, pp. 189-193. DOI: http://dx.doi.org/10.1177/1470357203002002004

[26] A.M. Ariffin, S. Norshuhada, Conceptual design model of Reality Learning Media (RLM), in: Proceedings of IADIS International Conference eSociety 2009, Barcelona, Spain, 2009. 
[27] F. van Gils, Potential applications of digital storytelling in education, in: Proceedings of 3rd Twente Student Conference on IT, University of Twente, 2005.

[28] H. Alborzi, A. Druin, J. Montemayor, M. Platner, J. Porteous, 1. Sherman, et al., Designing storyrooms: Interactive storytelling spaces for children, in: Proceeding of DIS '00. New York, 2000, pp. 95104.

[29] D. Leishman, Visual literacy and learning: Finding some online territories for the slow learner, On The Horizon, vol. 12, 2004, pp. 26-30. DOI: https://doi.org/10.1108/10748120410540472

[30] N. Churchill, L.C. Ping, G. Oakley, D. Churchill, Digital storytelling and digital literacy learning, in: Proceedings of International Conference on Information Communication Technologies in Education (ICICTE) 2008, 2008, pp. 418-430.

[31] N. Kaplan, Y. Chisik, K. Knudtzon, R. Kulkarni, S. Moulthrop, K. Summers, H. Weeks, Supporting sociable literacy in the International Children's Digital Library, in: Proceedings of Interaction Design and Children 2004, 2004, pp. 89-96.

[32] T.A. Zucker, A.K. Moody, M.C. McKenna, The effects of electronic books on pre-kindergarten-tograde 5 students' literacy and language outcomes: A research synthesis, Journal of Educational Computing Research, vol. 40, 2009, pp. 47-87.

[33] A. Shamir, O. Korat, R. Fellah, Promoting vocabulary, phonological awareness and concept about print among children at risk for learning disability: Can e-books help?, Reading and Writing, vol. 25, 2010, pp. 45-69. DOI: http://dx.doi.org/10.1007/s11145-010-9247-x

[34] O. Korat, A. Shamir, Electronic books versus adult readers: Effects on children's emergent literacy as a function of social class, Journal of Computer Assisted Learning, vol. 23, 2007, pp. 248-259. DOI: https://doi.org/10.1111/j.1365-2729.2006.00213.x

[35] R. Silverman, Investigating video as a means to promote vocabulary for at-risk children, Contemporary Educational Psychology, vol. 38, 2013, pp. 170-179. DOI: https://psycnet.apa.org/doi/10.1016/j.cedpsych.201 3.03.001

[36] M.T. de Jong, A.G. Bus, The Efficacy of Electronic Books in Fostering Kindergarten Children's Emergent Story Understanding, Reading Research Quarterly, vol. 39, 2004, pp. 378-393.

[37] M.T. de Jong, A.G. Bus, Quality of book-reading matters for emergent readers: An experiment with the same book in a regular or electronic format, Journal of Educational Psychology, vol. 94, 2002, pp. 145-155. DOI: https://doi.org/10.1037/0022$\underline{0663.94 .1 .145}$

[38] J. Parish-Morris, N. Mahajan, K. Hirsh-Pasek, R.M. Golinkoff, M.F. Collins, Once upon a time: Parentchild dialogue and storybook reading in the electronic era, Mind, Brain, and Education, vol. 7, 2013, pp. 200-211. DOI: https://doi.org/10.1111/mbe.12028

[39] O. Korat, A. Shamir, The educational electronic book as a tool for supporting children's emergent literacy in low versus middle SES groups, Computers \& Education, vol. 50, 2008, pp. 110 124.

DOI:

https://doi.org/10.1016/j.compedu.2006.04.002

[40] M.J.A.J. Verhallen, A.G. Bus, Low-income immigrant pupils learning vocabulary through digital picture storybooks, Journal of Educational Psychology, vol. 102, 2010, pp. 54-61. DOI: https://doi.org/10.1037/a0017133

[41] M.J.A.J. Verhallen, A.G. Bus, M.T. de Jong, The promise of multimedia stories for kindergarten children at risk, Journal of Educational Psychology, vol. 98, 2006, pp. 410-419. DOI: http://dx.doi.org/10.1037/0022-0663.98.2.410

[42] D. Smeets, A.G. Bus, Interactive electronic storybooks for kindergartners to promote vocabulary growth, Journal of Experimental Child Psychology, vol. 112, 2012, pp. 36-55. DOI: https://doi.org/10.1016/j.jecp.2011.12.003

[43] D. Smeets, A.G. Bus, The interactive animated ebook as a word learning device for kindergartners, Applied Psycholinguistics, vol. 22, 2014, pp. 1-22. DOI: https://doi.org/10.1017/S0142716413000556

[44] D. Smeets, M.J. van Dijken, Using electronic storybooks to support word learning in children with severe language impairments, Journal of Learning Disabilities, vol. 47, 2014, pp. 435-449. DOI: https://doi.org/10.1177/0022219412467069

[45] C.M. Ricci, C.R. Beal, The effect of interactive media on children's story memory, Journal of Educational Psychology, vol. 94, 2002, p. 138. DOI: https://psycnet.apa.org/doi/10.1037/00220663.94.1.138 